\title{
META-ANALYSIS OF CORRELATION BETWEEN BURNOUT AND WORK SATISFACTION IN NURSES
}

\author{
Arista Gunawati'), Agus Kristiyanto²), Hanung Prasetya3) \\ 1)Masters Program in Public Health, Universitas Sebelas Maret \\ 2)Faculty of Sport, Universitas Sebelas Maret \\ 3)Study Program of Acupuncture, Health Polytechnics, \\ Ministry of Health Surakarta
}

\begin{abstract}
Background: Current evidence reveals job satisfaction as a predictor of the length of stay in a job, motivation and job productivity. The main sources of nursing dissatisfaction include lack of staff, high care pressure, burn out, and lack of professional acknowledgement. Burnout explained the highest amount of variance in mental health of nurses. These are known to compromise productivity and performance, as well as affect the quality of patient care. This study aimed to investigate correlation between burnout and work satisfaction in nurses.

Subjects and Method: This meta-analysis used articles from the Google Scholar database, PubMed, Sciencedirect, published from 2010 to 2021. Eligibility criteria were defined using the PICO model as follows, (1) population= nurse, (2) intervention= high burnout, (3) comparison= low burnout, and (4) outcome $=$ work satisfaction. The keywords to collect the articles were ("job satisfaction" OR "work satisfaction" OR "occupational satisfaction") AND "job burnout" AND ("adjusted odds ratio" OR "multivariate analysis") AND "nurse." Inclusion criteria were full text, cross-sectional study, and reported adjusted odds ratio. The meta-analysis articles were written using the PRISMA rules. Data were analyzed using Revman $5 \cdot 3$

Results: There were four studies from China, Croatia, and Europe included in the inclusion criteria. This study found that high burnout lowered work satisfaction in nurses 0.56 times than those with low burnout $(\mathrm{aOR}=0.56 ; 95 \% \mathrm{CI}=0.26$ to 1.21 ; $\mathrm{p}<0.001)$
\end{abstract}

Conclusion: The higher burnout, the lower the work satisfaction in nurses.

Keywords: burnout, work satisfaction, nurse

\section{Correspondence:}

Arista Gunawati. Masters Program in Public Health, Universitas Sebelas Maret. Jl. Ir. Sutami 36A, Surakarta 57216, Central Java. Email: aristagunawati@gmail.com. Mobile: 085647093646. 